\title{
Burden-of-Illness Associated with Bleeding-Related Hospitalizations in Atrial Fibrillation Patients: Findings from the Nationwide Readmission Database
}

\author{
Benjamin Miao ${ }^{1,2}$ Monique Miller ${ }^{1}$ Belinda Lovelace ${ }^{3}$ Anne Beaubrun ${ }^{3}$ Kelly McNeil-Posey ${ }^{3}$ \\ Mark J. Alberts ${ }^{4}$ William Frank Peacock ${ }^{5}$ Olivia S. Costa ${ }^{1,2}$ Charles Michael White ${ }^{1,2}$ \\ Craig I. Coleman ${ }^{1,2}$
}

\footnotetext{
${ }^{1}$ Department of Pharmacy Practice, University of Connecticut School of Pharmacy, Storrs, Connecticut, United States

2 Evidence-Based Practice Center, Hartford Hospital, Hartford, Connecticut, United States

${ }^{3}$ Health Economics and Outcomes, Portola Pharmaceuticals, San Francisco, California, United States

4 Department of Neurology, Hartford Hospital, Hartford, Connecticut, United States

${ }^{5}$ Department of Emergency Medicine, Baylor College of Medicine, Houston, Texas, United States
}

TH Open 2020;4:e211-e217.
Address for correspondence Craig I. Coleman, PharmD, Hartford Hospital Evidence-Based Practice Center, UCONN/Hartford Hospital, 80 Seymour Street, Hartford, CT 06102, United States (e-mail: craig.coleman@hhchealth.org).

\begin{abstract}
Keywords

- hemorrhage

- bleeding

- atrial fibrillation

- outcomes

- burden-of-illness

Introduction A paucity of contemporary data examining bleeding-related hospitalization outcomes in atrial fibrillation (AF) patients exists.

Methods Adults in the Nationwide Readmissions Database (January 2016-November 2016) with AF and hospitalized for intracranial hemorrhage (ICH), gastrointestinal, genitourinary, or other bleeding were identified. Association between bleed types and outcomes were assessed using multivariable regression (gastrointestinal defined as referent) and reported as crude incidences and adjusted odds ratios (ORs) or mean differences with $95 \%$ confidence intervals (Cls).

Results In total, 196,878 index bleeding-related hospitalizations were identified in this AF cohort (CHA2DS2VASc score $\geq 2$ in $95.1 \%$ ), with $70.8 \%$ classified as gastrointestinal. The overall incidences of in-hospital mortality, need for post-discharge out-of-home care, and 30-day readmission were $4.9,50.8$, and $18.2 \%$, respectively. Multivariable regression suggested traumatic and nontraumatic ICHs were associated with higher odds of inhospital mortality $(\mathrm{OR}=3.99,95 \% \mathrm{Cl}=3.79,4.19$; $\mathrm{OR}=13.09,95 \% \mathrm{Cl}=12.24,13.99)$ and need for post-discharge out-of-home care $(\mathrm{OR}=2.92,95 \% \mathrm{Cl}=2.83,3.01 ; \mathrm{OR}=2.74$, $95 \% \mathrm{Cl}=2.59,2.90$ ), and increases in mean index hospitalization length-of-stay (8.31 days, $95 \% \mathrm{Cl}=8.03,8.60,6.27$ days, $95 \% \mathrm{Cl}=5.97,6.57)$ versus gastrointestinal bleeding. Genitourinary and other bleeds were associated with lower mortality $(O R=0.37,95 \%$ $\mathrm{Cl}=0.25,0.55 ; \mathrm{OR}=0.59,95 \% \mathrm{Cl}=0.53,0.64)$ and reduced length-of-stays ( -2.84 days, $95 \% \mathrm{Cl}=-2.91,-2.76 ;-2.06$ days, $95 \% \mathrm{Cl}=-2.11,-2.01)$ versus gastrointestinal bleeding. Genitourinary bleeds were also associated with a reduced need for post-discharge out-of-home care $(\mathrm{OR}=0.86,95 \% \mathrm{Cl}=0.77,0.97)$.
\end{abstract}

received

March 16, 2020

accepted

August 5, 2020
DOI https://doi.org/

10.1055/s-0040-1716549. ISSN 2512-9465. (c) 2020 Georg Thieme Verlag KG Stuttgart · New York
License terms

(c) (i) 
Conclusion The burden of bleeding-related hospitalizations was notably driven by relatively rare but severe and life-threatening $\mathrm{ICH}$, and less morbid but more frequent gastrointestinal bleeding. There is need for continued research on bleeding risk factors and mitigation techniques to avoid bleeding-related patient hospitalizations.

\section{Introduction}

Oral anticoagulants can prevent most ischemic strokes in patients with atrial fibrillation (AF); however, fear of severe or life-threatening (and even minor) bleeds, a perceived high risk of bleeding on oral anticoagulation in frail or higher fall risk patients and the effort required to monitor oral anticoagulants are among the most cited reasons for their persistent underutilization. While the absolute risk is low, oral anticoagulants remain a common cause of bleedingrelated hospitalizations. ${ }^{1-5}$ In one real-world study of patients with AF who were treated with oral factor Xa inhibitors, those who were hospitalized with a major bleed of any type were found to have mean hospital stays exceeding 5 days and inpatient mortality rates of approximately $3 \%$, though mortality risk was notably higher for patients with intracranial hemorrhage (ICH) (approximately 14\%). ${ }^{4}$

There is a scarcity of nationally representative data describing the incidence and burden-of-illness of bleeding-related hospitalizations in AF patients, both overall and by bleed subtype. The availability of contemporary data on this topic would allow clinicians and other decision-makers to better understand the absolute and relative risks of detrimental outcomes across various bleeding-related hospitalization types. Thus, this study sought to evaluate incidence rates and subsequent outcomes associated with bleeding-related hospitalizations, overall and by bleeding subtype, among patients with AF. Though the dataset used for this analysis does not contain data on anticoagulant use, we limited the present analysis to AF patients as they are considered higher risk for thrombosis and should be treated with oral anticoagulation in all but the lowest risk patients. ${ }^{1}$

\section{Methods}

We performed a retrospective cohort analysis using data from the 2016 U.S. Agency for Healthcare Research and Quality, Healthcare Cost and Utilization Project (HCUP) Nationwide Readmissions Database (NRD). The 2016 NRD includes a full calendar year of data with hospital discharge/ patient characteristics and diagnosis and procedure codes reported using the International Classification of Diseases10th Revision-Clinical Modification or Procedural Coding System (ICD-10-CM or -PCS). The 2016 NRD contains up to 35 ICD-10-CM diagnosis codes and 15 procedural codes for each encounter. The database provides nationally representative information on hospital admissions for all patient ages and readmissions that take place in the same state as the index hospitalization. ${ }^{6}$ Unweighted, the NRD contains data for approximately 17 million discharges each year. Weighted, it estimates roughly 35 million discharges from 27 geographically dispersed states, accounting for $57.8 \%$ of the total U.S. resident population and $56.6 \%$ of all U.S. hospitalizations.

We identified patients with an ICD-10-CM code for AF, who were $\geq 18$ years-of-age and had an index hospitalization for a bleeding event between January 1, 2016 and November 30, 2016 (with the November 30th cut-off utilized to allow for assessment of 30-day readmission outcomes in the 2016 calendar year) (-Supplementary Table S1). An index bleeding-related hospitalization was defined as a patient's first hospitalization with a primary ICD-10-CM diagnosis code from the Cunningham ${ }^{7}$ or $\operatorname{Joos}^{8}$ algorithms indicating bleeding or select nonprimary diagnosis codes from Cunningham ${ }^{7}$ indicating bleeding if accompanied by a transfusion-related code ( - Supplementary Tables S2-S4). Bleeding-related hospitalizations were further stratified into bleeding subtype cohorts of nontraumatic $\mathrm{ICH}$, traumatic $\mathrm{ICH}$, gastrointestinal, genitourinary, or other bleeding (e.g., hemopericardium, hemoperitoneum, hemarthrosis, unspecified hemorrhage).

Clinical outcomes evaluated in this study included the rate of bleeding-related hospitalizations (per 100,000 adult persons, assuming $244,945,724$ adults in the United States in $2016^{9}$ ), the proportion of patients dying prior to discharge (inpatient mortality), index hospitalization length-of-stay (LOS), the proportion requiring post-discharge out-ofhome care at an intermediate care facility (ICF), inpatient rehabilitation facility or skilled nursing facility, and the proportion of patients surviving to discharge readmitted for any cause, subsequent bleeding or a thrombotic event (ischemic stroke, myocardial infarction, or venous thromboembolism) within 30-days of the index hospital discharge (and within the 2016 calendar year). A sensitivity analysis was also performed whereby we restricted eligible index bleeding-related hospitalizations to those patients having an ICD-10-CM diagnosis code indicating an antithromboticrelated bleeding event (D68.32, T45.515x, or T45.525x).

Baseline patient characteristics and outcomes were analyzed using descriptive statistics. Categorical data were presented as percentages, while continuous data were summarized as means \pm standard deviation and/or medians with $25 \%, 75 \%$ ranges. We evaluated both absolute and relative associations between bleeding-related hospitalization types (i.e., traumatic and nontraumatic ICH, gastrointestinal, genitourinary, and other bleeding) and outcomes. We assessed binary study outcomes (inpatient mortality and need for post-discharge out-ofhome care) with and without adjustment for age (continuous), sex, history of stroke, thrombocytopenia, anemia, heart failure, cancer, coagulopathy, obesity, alcohol abuse, hypertension, chronic kidney disease, and diabetes (all binary) using 
multivariable logistic regression. Results were reported as crude and adjusted odds ratios (ORs), respectively, with 95\% confidence intervals (CIs). Generalized linear regression (using a gamma-distributed error and log-link) was used to evaluate associations between bleeding-related hospitalization types and the continuous outcome of index hospitalization LOS with and without adjustment for baseline demographics and comorbidities (same covariates as for binary outcomes). Results on generalized linear regression were reported as the crude and adjusted absolute mean differences with $95 \% \mathrm{CIs}$. For all regression analyses, gastrointestinal bleeding was set as referent (as it was the most common cause of bleeding-related hospitalizations). All data management and statistical analyses were performed using SAS version 9.4 (SAS Institute Inc., Cary, North Carolina, United States) and IBM SPSS Statistics version 26.0 (IBM Corp, Armonk, New York, United States).

Since data were de-identified and in compliance with the Health Insurance Portability and Accountability Act (HIPAA) of 1996 to preserve participant anonymity and confidentiality, our study was deemed exempt from Institutional Review Board oversight. The preparation of the study report was done in accordance with the RECORD (REporting of studies Conducted using Observational Routinely collected health Data) statement. ${ }^{10}$

\section{Results}

The 2016 NRD core file contained data on 35,660,906 hospitalizations; 32,571,561 occurred between January 1, 2016 and November 30, 2016. Of these, 196,878 hospitalizations (80.4 events/100,000 persons) were bleeding-related and occurred within AF patients ( - Fig. 1). The median age of the cohort was $80(72,86)$ years. Overall and bleeding subtype incidences increased with increasing patient age (-Supplementary Fig. S1). The median CHA2DS2VASC score was $4(3,5)$ and modified HASBLED score was $3(3,4)$. Ninety-five percent of this AF cohort had a CHA2DS2VASc score $\geq 2$. Gastrointestinal bleeding (70.9\%) was the most frequent bleeding-related hospitalization type followed by other bleeding (13.1\%), traumatic
ICH (12.0\%), nontraumatic ICH (3.0\%), and genitourinary bleeding $(1.1 \%)$ (-Table 1$)$.

\section{Crude Incidences}

Patients with ICH (traumatic and nontraumatic) experienced a high risk of in-hospital mortality (12.4 and 29.3\%) and long index hospital LOS ( $\geq 6.95$ days) ( - Table 2). ICH was also associated with a substantial proportion of patients requiring out-of-home care (45.1\%) as evidenced by discharge to a secondary treatment facility. Of patients experiencing a gastrointestinal bleed-related hospitalization, 3.2\% died inhospital. Index hospital LOS averaged $5.2 \pm 5.5$ days and $22.2 \%$ required post-discharge out-of-home care. Genitourinary and other bleeds had in-hospital mortality rates ranging from 1.2 to $2.0 \%$, mean LOS ranging from 4.3 to 4.5 days and 16.9 to $26.4 \%$ needed post-discharge out-of-home care. Approximately $18 \%$ of patients experiencing a bleedingrelated hospitalization were readmitted for any cause within 30-days of discharge, with readmission for subsequent or rebleeding occurring in 3.8\% and a thrombotic event in 1.0\% of patients. Among gastrointestinal bleed patients readmitted for a subsequent bleed with 30-days $(n=5690)$, nearly all (98.9\%) were for a subsequent gastrointestinal bleed.

\section{Adjusted Odds Ratios}

Upon multivariable regression analysis, the adjusted odds for in-hospital mortality were statistically significantly higher among patients experiencing a traumatic (adjusted $\mathrm{OR}=3.99$ ) or nontraumatic ICH (adjusted $\mathrm{OR}=13.09$ ) compared with gastrointestinal bleeding ( - Table 3 ). Conversely, the adjusted ORs of in-hospital mortality were significantly lower for patients with genitourinary and other bleeds (adjusted $\mathrm{ORs}=0.37$ and 0.58 , respectively) versus gastrointestinal bleeding. Traumatic and nontraumatic ICHs were also associated with significant increases in index hospitalization LOS (adjusted mean differences $=8.31$ days and 6.86 days) compared with gastrointestinal bleeding. Genitourinary and other bleeds were associated with significantly reduced index hospital LOS (adjusted mean differences $=-3.17$ days and -1.84

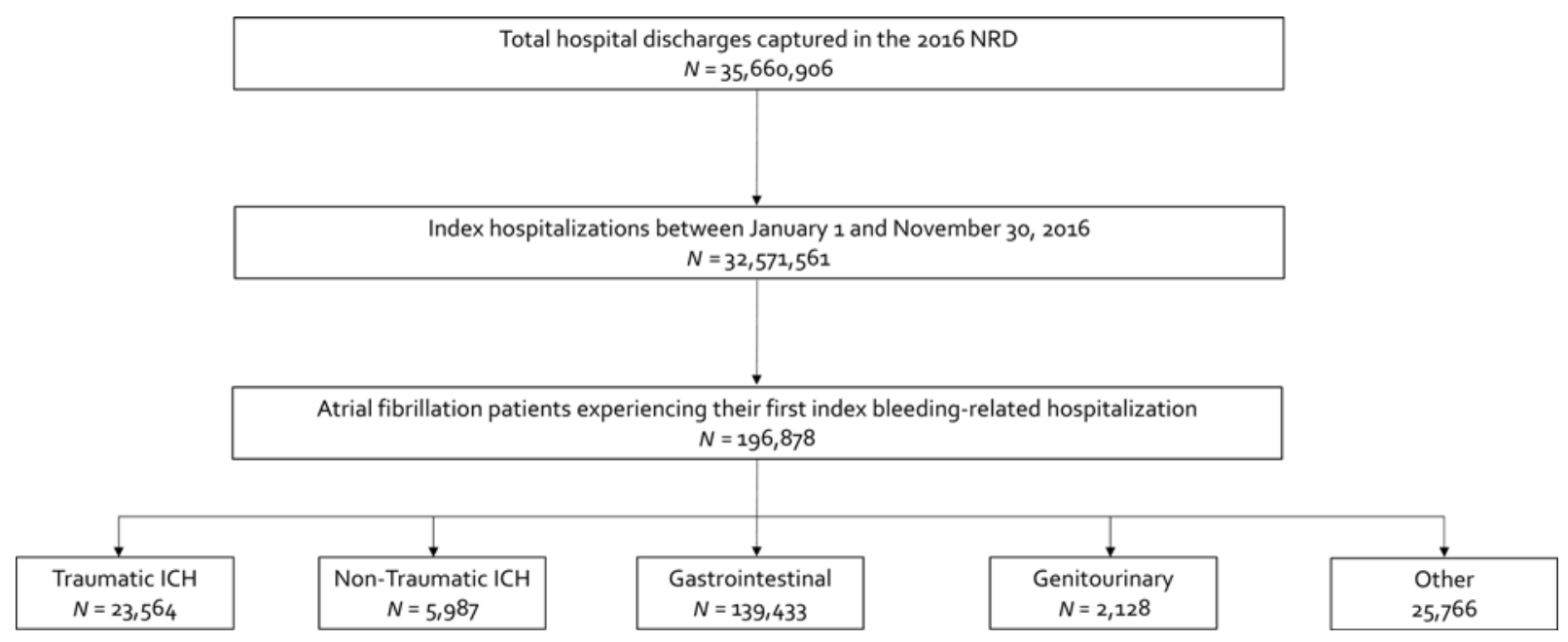

Fig. 1 Flow diagram of patient selection. 
e214 Bleeding-Related Hospitalizations in Atrial Fibrillation Patients Miao et al.

Table 1 Baseline characteristics

\begin{tabular}{|c|c|c|c|c|c|c|}
\hline & $\begin{array}{l}\text { All bleeding-related } \\
\text { hospitalizations } \\
N=196,878 \\
n(\%)\end{array}$ & $\begin{array}{l}\text { Traumatic } \\
\text { ICH } \\
N=23,564 \\
n(\%)\end{array}$ & $\begin{array}{l}\text { Nontraumatic } \\
\text { ICH } \\
N=5,987 \\
n(\%)\end{array}$ & $\begin{array}{l}\text { GI bleeds } \\
N=139,433 \\
n(\%)\end{array}$ & $\begin{array}{l}\text { GU bleeds } \\
N=2,128 \\
n(\%)\end{array}$ & $\begin{array}{l}\text { Other } \\
N=25,766 \\
n(\%)\end{array}$ \\
\hline $\begin{array}{l}\text { Age (median, } 25 \text { th, } \\
\text { 75th percentile) }\end{array}$ & $80(72,86)$ & $82(75,88)$ & $80(70,86)$ & $79(72,86)$ & $74(61,84)$ & $79(70,86)$ \\
\hline $65-74 y$ & $4,331(22.0)$ & $3,999(17.0)$ & $1,280(21.4)$ & $31,686(22.7)$ & $441(20.7)$ & $5,925(23.0)$ \\
\hline$\geq 75 y$ & $131,467(66.8)$ & $17,753(75.3)$ & $3,893(65.0)$ & $92,333(66.2)$ & $1,036(48.7)$ & $16,451(63.8)$ \\
\hline Sex: Female & $94,438(48.0)$ & $10,385(44.1)$ & 2,909 (48.6) & $67,058(48.1)$ & $1,130(53.1)$ & $12,956(50.3)$ \\
\hline \multicolumn{7}{|l|}{ Comorbidities } \\
\hline Alcohol abuse & $7,888(4.0)$ & $1,404(6.0)$ & $187(3.1)$ & $5,571(4.0)$ & $58(2.7)$ & $669(2.7)$ \\
\hline Anemia & 54,835 (27.9) & $4,981(21.1)$ & $944(15.8)$ & $45,614(32.7)$ & $503(23.7)$ & $2,793(10.8)$ \\
\hline Heart failure & 76,967 (39.1) & $7,004(29.7)$ & $1,539(25.7)$ & $55,974(40.1)$ & $736(34.6)$ & $11,715(45.5)$ \\
\hline Thrombocytopenia & $14,683(7.5)$ & $2,374(10.1)$ & $387(6.5)$ & $10,040(7.2)$ & $122(5.7)$ & $1,760(6.8)$ \\
\hline Coagulopathy & $24,019(12.2)$ & $3,548(15.1)$ & $668(11.2)$ & $16,408(11.8)$ & $232(10.9)$ & $3,163(12.3)$ \\
\hline Diabetes & $66,968(34.0)$ & $7,034(29.8)$ & $2,061(34.4)$ & $47,966(34.4)$ & $652(30.6)$ & $9,256(35.7)$ \\
\hline Hypertension & $161,769(82.2)$ & $19,169(81.3)$ & $5,279(88.2)$ & $115,101(82.5)$ & $1,281(60.2)$ & $20,939(81.3)$ \\
\hline Hypothyroidism & $40,431(20.5)$ & 4,933 (20.9) & $1,088(18.2)$ & $28,510(20.4)$ & $353(16.6)$ & $5,547(21.5)$ \\
\hline Liver disease & $10,775(5.5)$ & $707(3.0)$ & 113 (1.9) & $8,588(6.2)$ & $89(4.2)$ & $1,277(5.0)$ \\
\hline Metastatic cancer & $4,253(2.2)$ & $316(1.3)$ & $162(2.7)$ & $3,102(2.2)$ & $66(3.1)$ & $607(2.4)$ \\
\hline Obesity & $25,696(13.1)$ & $1,488(6.3)$ & $649(10.8)$ & 19,406 (13.9) & $374(17.6)$ & $3,778(14.7)$ \\
\hline $\begin{array}{l}\text { Peripheral } \\
\text { vascular disease }\end{array}$ & $25,607(13.0)$ & $2,349(10.0)$ & $618(10.3)$ & $18,979(13.6)$ & $278(13.1)$ & $3,383(13.1)$ \\
\hline Ischemic stroke & $1,880(1.0)$ & $558(2.4)$ & $386(6.5)$ & $818(0.6)$ & $16(0.8)$ & $1,102(0.4)$ \\
\hline Renal impairment & $65,084(33.1)$ & $5,541(23.5)$ & $1,320(22.1)$ & $48,112(34.5)$ & $424(19.9)$ & $9,687(37.7)$ \\
\hline CKD stage 3 or worse & $49,498(25.1)$ & $3,871(16.4)$ & $960(16.0)$ & $37,007(26.5)$ & $322(15.2)$ & $7,338(28.5)$ \\
\hline Solid tumors & $5,971(3.0)$ & $398(1.7)$ & $145(2.4)$ & $4,293(3.1)$ & $123(5.8)$ & $1,012(3.9)$ \\
\hline Lymphoma & $2,005(1.0)$ & $148(0.6)$ & $43(0.7)$ & $1,486(1.1)$ & $18(0.9)$ & $311(1.2)$ \\
\hline $\begin{array}{l}\text { Peptic ulcer disease } \\
\text { without bleeding }\end{array}$ & $3,554(1.8)$ & $149(0.6)$ & $41(0.7)$ & $1,921(1.4)$ & $17(0.8)$ & $1,425(5.5)$ \\
\hline $\begin{array}{l}\text { CHA2DS2VASc score } \\
\text { (median, 25th, } \\
\text { 75th percentile) }\end{array}$ & $4(3,5)$ & $4(3,5)$ & $4(3,5)$ & $4(3,5)$ & $3(2,4)$ & $4(3,5)$ \\
\hline CHA2DS2VASc $\geq 2$ & $187,233(95.1)$ & $22,390(95.0)$ & $5,685(94.9)$ & $132,768(95.2)$ & $1,830(86.0)$ & $24,561(95.3)$ \\
\hline $\begin{array}{l}\text { Modified HASBLED score } \\
\text { (median, 25th, } \\
\text { 75th percentile) }\end{array}$ & $3(3,4)$ & $3(3,4)$ & $3(3,3)$ & $3(3,4)$ & $3(2,3)$ & $3(3,4)$ \\
\hline Modified HASBLED $\geq 3$ & $161,792(82.2)$ & $19,368(82.2)$ & $4,982(83.2)$ & $115,384(82.8)$ & $1,269(59.6)$ & $20,789(80.7)$ \\
\hline
\end{tabular}

Abbreviations: CKD, chronic kidney disease; $\mathrm{Gl}$, gastrointestinal; $\mathrm{GU}$, genitourinary; ICH, intracranial hemorrhage.

days) versus gastrointestinal bleeding. Traumatic and nontraumatic ICH and other bleeds were found to be associated with significantly increased odds of needing subsequent postdischarge out-of-home care (adjusted ORs = 3.12, 2.84, and 1.26 , respectively). Genitourinary bleeds were associated with a significantly reduced odds of needing out-of-home care compared with gastrointestinal bleeding (adjusted $\mathrm{OR}=0.70$ ).

\section{Sensitivity Analysis}

Upon sensitivity analysis, we identified 20,103 patients (10.2\%) with a billing code indicating antithrombotic-related bleeding (-Supplementary Table S5). Gastrointestinal bleed- ing (66.5\%) was the most frequent bleeding subtype in this restricted cohort, followed by other bleeding (22.5\%), traumatic ICH $(7.3 \%)$, nontraumatic ICH (2.2\%), and genitourinary bleeding (1.5\%). Crude incidence of outcomes in this sensitivity analysis cohort is depicted in - Supplementary Table S6.

\section{Discussion}

In this large, real-world study of nearly 200,000 AF patients hospitalized for bleeds, we found that bleeding-related hospitalizations are associated with differing levels of detrimental clinical consequences across various bleed types. 
Table 2 Crude incidence of outcomes in patients experiencing a bleeding-related hospitalization

\begin{tabular}{|c|c|c|c|c|c|c|}
\hline & $\begin{array}{l}\text { All bleeding-related } \\
\text { hospitalizations } \\
N=196,878 \\
n(\%)\end{array}$ & $\begin{array}{l}\text { Traumatic } \\
\text { ICH } \\
N=23,564 \\
n(\%)\end{array}$ & $\begin{array}{l}\text { Nontraumatic ICH } \\
N=5,987 \\
n(\%)\end{array}$ & $\begin{array}{l}\text { Gl bleeds } \\
N=139,433 \\
n(\%)\end{array}$ & $\begin{array}{l}\text { GU bleeds } \\
N=2,128 \\
n(\%)\end{array}$ & $\begin{array}{l}\text { Other } \\
N=25,766 \\
n(\%)\end{array}$ \\
\hline In-hospital mortality & $9,720(4.9)$ & $2,921(12.4)$ & $1,755(29.3)$ & $4,503(3.2)$ & $26(1.2)$ & $515(2.0)$ \\
\hline $\begin{array}{l}\text { Index hospital length-of-stay, } \\
\text { days, mean } \pm \text { SD } \\
\text { (median, } 25 \%, 75 \% \text { range) }\end{array}$ & $\begin{array}{l}5.45 \pm 6.31 \\
{[4(2,6)]}\end{array}$ & $\begin{array}{l}7.77 \pm 9.93 \\
{[5(3,9)]}\end{array}$ & $\begin{array}{l}6.95 \pm 8.87 \\
{[4(2,9)]}\end{array}$ & $\begin{array}{l}5.19 \pm 5.46 \\
{[4(2,6)]}\end{array}$ & $\begin{array}{l}4.30 \pm 4.20 \\
{[3(2,5)]}\end{array}$ & $\begin{array}{l}4.48 \pm 5.13 \\
{[3(2,5)]}\end{array}$ \\
\hline \multicolumn{7}{|l|}{ Other discharge disposition } \\
\hline $\begin{array}{l}\text { Routine discharge or } \\
\text { destination unknown }\end{array}$ & $98,104(49.8)$ & $5,402(22.9)$ & $983(16.4)$ & $77,212(55.4)$ & $1,384(65.0)$ & $13150(51.0)$ \\
\hline Short-term hospital & $1,826(0.9)$ & $280(1.2)$ & $117(2.0)$ & $1,173(0.8)$ & $18(0.8)$ & $238(0.9)$ \\
\hline $\begin{array}{l}\text { Other: SNF, ICF, another } \\
\text { type of facility }\end{array}$ & $50,035(25.4)$ & $10,533(44.7)$ & $2,405(40.2)$ & $30,186(21.6)$ & $342(16.1)$ & $6569(25.5)$ \\
\hline Home health care & $35,756(18.2)$ & $4,253(18.0)$ & $705(11.8)$ & $25,363(18.2)$ & $361(17.0)$ & $5074(19.7)$ \\
\hline Against medical advice & $1,360(0.7)$ & $155(0.7)$ & $23(0.4)$ & $946(0.7)$ & $22(1.0)$ & $215(0.8)$ \\
\hline $\begin{array}{l}\text { Readmission for any cause } \\
\text { within } 30 \mathrm{~d} \text { of } \\
\text { hospital discharge and within } \\
\text { the } 2016 \text { calendar year }^{\mathrm{a}}\end{array}$ & $35,899(18.2)$ & $3,703(15.7)$ & $683(11.4)$ & $25,869(18.6)$ & $407(19.1)$ & $5236(20.3)$ \\
\hline $\begin{array}{l}\text { 30-d readmission for a } \\
\text { subsequent major bleeding }\end{array}$ & $7,383(3.8)$ & $789(3.3)$ & $48(0.8)$ & $5,690(4.1)$ & $36(1.7)$ & $820(3.2)$ \\
\hline $\begin{array}{l}\text { 30-d readmission for } \\
\text { thrombotic event } \\
\text { (ischemic stroke, MI, DVT, PE] }\end{array}$ & $1,964(1.0)$ & $235(1.0)$ & $108(1.8)$ & $1,348(1.0)$ & $17(0.8)$ & $255(1.0)$ \\
\hline
\end{tabular}

Abbreviations: DVT, deep vein thrombosis; GI, gastrointestinal; GU, genitourinary; ICF, intermediate care facility; ICH, intracranial hemorrhage; MI, myocardial infarction; PE, pulmonary embolism; SD, standard deviation; SNF, skilled nursing facility.

a Percentage based on number of patients surviving the index hospitalization.

Table 3 Crude and adjusted odds ratios for outcomes stratified on bleed type

\begin{tabular}{|l|l|l|l|l|l|l|}
\hline \multirow{2}{*}{} & \multicolumn{2}{|l|}{ In-hospital mortality } & \multicolumn{2}{l|}{$\begin{array}{l}\text { Post-discharge out-of-hos- } \\
\text { pital care }\end{array}$} & \multicolumn{2}{l|}{ Index hospital length-of-stay } \\
\cline { 2 - 7 } & Crude OR & Adjusted OR & Crude OR & Adjusted OR & $\begin{array}{l}\text { Mean day(s) } \\
\text { difference }\end{array}$ & $\begin{array}{l}\text { Adjusted mean } \\
\text { day(s) difference }\end{array}$ \\
\hline Gastrointestinal & Referent & Referent & Referent & Referent & Referent & Referent \\
\hline Traumatic ICH & $\begin{array}{l}4.24 \\
(4.04,4.45)\end{array}$ & $\begin{array}{l}3.99 \\
(3.79,4.19)\end{array}$ & $\begin{array}{l}2.92 \\
(2.84,3.01)\end{array}$ & $\begin{array}{l}2.92 \\
(2.83,3.01)\end{array}$ & $\begin{array}{l}2.68 \\
(2.63,2.73)\end{array}$ & $\begin{array}{l}(8.31 \\
(8.03,8.60)\end{array}$ \\
\hline Nontraumatic & 12.42 & 13.09 & 2.51 & 2.74 & 2.15 & 6.27 \\
ICH & $(11.66,13.23)$ & $(12.24,13.99)$ & $(2.38,2.64)$ & $(2.59,2.90)$ & $(2.03,2.28)$ & $(5.97,6.57)$ \\
\hline Genitourinary & 0.38 & 0.37 & 0.70 & 0.86 & -0.89 & -2.84 \\
& $(0.26,0.55)$ & $(0.25,0.55)$ & $(0.63,0.79)$ & $(0.77,0.97)$ & $(-1.00,-0.76)$ & $(-2.91,-2.76)$ \\
\hline Other & 0.61 & $\begin{array}{l}0.58 \\
(0.53,0.64)\end{array}$ & $\begin{array}{l}1.24 \\
(1.20,1.28)\end{array}$ & $\begin{array}{l}1.30 \\
(1.26,1.34)\end{array}$ & $\begin{array}{l}-0.70 \\
(-0.72,-0.68)\end{array}$ & $(-2.11,-2.01)$ \\
\hline
\end{tabular}

Abbreviations: $\mathrm{Cl}$, confidence interval; ICH, intracranial hemorrhage; OR, odds ratio.

Gastrointestinal bleeds were identified as the underlying cause of nearly three-quarters of all bleeding-related hospitalizations in this study but was associated with less mortality and morbidity compared with ICH. While ICH was relatively uncommon, it was associated with the greatest odds of in-hospital mortality, longer LOS, and a more frequent need for post-discharge out-of-home care. Both genitourinary and other bleeds were also relatively uncommon causes of bleeding-related hospitalizations compared with gastrointestinal bleeds. They were generally associated with the least severe outcomes of all bleeding types assessed (although genitourinary bleeds were associated with the highest readmissions for any reason within 30 days).

Our data suggest that even among patients experiencing an $\mathrm{ICH}$, the risk of mortality and morbidity within patients can vary. Within ICH-related hospitalizations, we found nontraumatic ICH patients had poorer outcomes compared with traumatic ICH patients, although patients with traumatic ICH had longer hospital LOS. Siddique et al ${ }^{11}$ previously showed the 6-month risk of death and moderate-to-severe 
disability (according to the Glasgow Outcome Scale) to be higher in patients experiencing a nontraumatic ICH versus a traumatic ICH (39.5 vs. $25.6 \%$ for death; 49.3 vs. $39.5 \%$ for moderate-to-severe disability). Our study reinforces the findings observed in Siddique et al but also extends them by adding healthcare utilization data. Our data suggest nontraumatic ICH is associated with nearly twice the mortality rate and three times the risk of readmission for bleeding at 30 days versus traumatic ICH. Moreover, we observed modest increases in index hospital LOS with nontraumatic versus traumatic ICH. Although we were unable to assess for the presence of disability in our study, we did observe that only $24.5 \%$ of the patients with nontraumatic ICH were discharged home (with or without home health care services) compared with $40.3 \%$ of patients hospitalized for a traumatic ICH. These findings suggest $\mathrm{ICH}$, in general, was associated with considerable morbidity.

Gastrointestinal bleeding was the cause of bleeding-related hospitalization in $70.8 \%$ of patients in our cohort. While billing codes potentially allow for the determination of the specific type of gastrointestinal bleeding (e.g., gastroduodenal, esophageal, upper, lower), as many as one-third of gastrointestinal bleeds are coded in a fashion that does not allow determination of even general anatomical location (e.g., ICD-10 K92.2 = "Gastrointestinal hemorrhage, unspecified"). ${ }^{7}$ For this reason, we did not attempt to evaluate outcomes stratified by gastrointestinal bleeding type/location. Given the large number of detected bleeds in our study that were gastrointestinal in nature, we assessed the proportion of all 30-day readmissions that were due to a subsequent gastrointestinal bleed. Our data suggest that nearly all subsequent bleeding events in the index gastrointestinal bleed population, were again, gastrointestinal in nature.

While the NRD does not provide data on medications used prior to (or during) admission, ICD-10-CM billing codes specifically identifying antithrombotic-related bleeding events exist (D68.32, T45.515x, and T45.525x) and we performed a sensitivity analysis whereby we restricted the population to patients with at least one of these billing codes. A code indicating antithrombotic-related bleeding was identified in only $10.2 \%$ of the overall bleeding-related hospitalization cohort, with crude incidences of outcomes appearing generally in line with the overall cohort. A previous study by Shehab et al assessed the accuracy of ICD-10-CM codes to identify antithrombotic-related bleeding hospitalizations in Medicare fee-forservice beneficiaries who were hospitalized for a major bleed at one of five hospitals across three states and found they yielded only a moderate positive predictive value $(71.4 \%)$ and poor sensitivity (6.8\%). ${ }^{12}$ As with the study conducted by Shehab, it is likely that the number of antithrombotic-related bleed is artificially low due to underutilization of corresponding codes. Given the high thrombotic risk nature of our study cohort (all with AF at presentation, $>95 \%$ with a CHA2DS2VASc score $\geq 2$ ), we would anticipate a large portion of patients were receiving an oral anticoagulant at baseline. ${ }^{13,14}$ Data from the International Global Anticoagulant Registry in the FIELD (GARFIELD)AF and the United States National Outcomes Registry for Better Informed Treatment of Atrial Fibrillation (ORBIT-AF) both depicted relatively high oral anticoagulant utilization, with 56 to $65 \%$ of AF patients with a CHA2DS2VASc $=1$ and 70 to $87 \%$ with a CHA2DS2VASc $\geq 2$ receiving oral anticoagulation. ${ }^{13}$ This suggests the diagnosis of AF may serve as a reasonable proxy for oral anticoagulant use. However, underutilization of oral anticoagulation therapy among patients with AF is likely still suboptimal in specific cohorts. The American College of Cardiology's Practice Innovation and Clinical Excellence (PINNACLE) registry demonstrated the prevalence of oral anticoagulant use (from 2008 to 2012) did not exceed 50.6\% even in patients with AF and a CHA2DS2-VASc score exceeding $4 .^{14}$ Importantly, since we limited this study to AF patients only, our findings are less generalizable to bleeding-related hospitalizations in other populations who may receive oral anticoagulation (e.g., venous thromboembolism).

Our study has limitations worthy of discussion. First, as with all retrospective administrative claims-based analyses, the influence of both selection bias (i.e., distortion in a measure of association due to a sample selection that does not accurately reflect the target population) and misclassification bias (i.e., classification of an individual, value, or attribute into a category other than that to which it belongs) on the study's internal validity need to be considered. ${ }^{15}$ The NRD captures all inpatients discharges in 27 geographically diverse states that participate in the HCUP State Inpatient Databases. This sample is then statistically weighted to make it representative of all inpatient discharges (nonrehabilitation or long-term acute care facility) at U.S. hospitals. ${ }^{5}$ The use of published, validated coding algorithms by Cunningham et $\mathrm{al}^{7}$ (overall algorithm positive predictive value of $89 \%$ ) and Joos et $\mathrm{al}^{8}$ (algorithm sensitivity of $91.4 \%$ and specificity of $90.2 \%$ ) to identify bleeding-related hospitalizations were utilized to reduce the risk of misclassification bias in our study and is a reasonable proxy for clinically relevant, if not major bleeding. Second, the NRD lacks data on medication use, disability assessment, diagnostic tests (e.g., endoscopy reports), and laboratory values (e.g., hematocrit/hemoglobin). As noted above, we attempted to overcome many of these limitations through the use of various billing code algorithms (likely with varying success) as well as through the use of proxy outcomes (i.e., assessment of the need for post-discharge out-of-home care in lieu of formal disability assessments or scales). Future studies using datasets with detailed pharmacy claims or drug utilization data that can overcome such limitations are warranted to confirm our findings. Subtypes of ICH were not consistently reported in the NRD therefore we were unable to contrast outcomes of intracerebral, subdural, and subarachnoid hemorrhages. Finally, the NRD only allows the identification of readmissions that occurred in the same state (and year) as the index hospitalization. Thus, our study may underestimate readmission rates. ${ }^{6}$

\section{Conclusion}

This large study suggests that in AF patients, bleeding-related hospitalizations were associated with a substantial burdenof-illness. Burden was notably driven by relatively rare, but 
severe and/or life-threatening ICH. While being the most frequently observed bleeding-related hospitalization cause, gastrointestinal bleeding was infrequently associated with in-hospital mortality or need for out-of-home post-discharge care. We found ICH to be associated with increased odds of in-hospital mortality, extended LOS, and post-discharge out-of-home care compared with gastrointestinal bleeding, while genitourinary and other bleeds appeared to be associated with the least detrimental outcomes. This study provides much needed, nationally representative and contemporary data on in-hospital and 30-day clinical outcomes of bleeding-associated hospitalizations in AF patients, both overall and by bleed subtype. These findings provide clinicians and other healthcare decision-makers needed data on absolute and relative risks of detrimental outcomes by bleeding-related hospitalization type. Further, our study emphasizes the need for continued research on bleeding risk factors and mitigation techniques to avoid bleedingrelated patient hospitalizations.

\section{Funding}

Funding was provided by Portola Pharmaceuticals, South San Francisco, California, United States. The funders of this study had no role in study design, data collection, data analysis, data interpretation, or writing of the report. All authors have approved the final manuscript.

\section{Conflict of Interest}

C.I.C. has received research funding and honoraria from Portola Pharmaceuticals, Inc., Bayer AG, and Janssen Scientific Affairs LLC. M.J.A. reports consultancy or speaker fees and honoraria from Genentech, Janssen Pharmaceuticals, Boehringer Ingelheim (modest), Pfizer, Bristol-Myers Squibb, Medscape, Portola, and patents/royalties from Duke University. B.L., A.B., and K.M.P. are employees of Portola Pharmaceuticals. W.F.P. has received grants and consulting fees from Abbott, Alere, Banyan, Cardiorentis, Janssen, Portola, Pfizer, Roche, and ZS Pharma; Beckman, Boehringer-Ingelheim, Instrument Labs, Phillips, Prevencio, Singulex and The Medicine's Company, and also has ownership interests at the Comprehensive Research Associate LLC, Emergencies in Medicine LLC. B.M., M.M., O.S.C., and C.M.W. declare they have no conflict of interest.

\section{References}

1 Kirchhof P, Benussi S, Kotecha DESC Scientific Document Group. , et al; 2016 ESC guidelines for the management of atrial fibrillation developed in collaboration with EACTS. Eur Heart J 2016;37(38): 2893-2962
2 Jakobsen M, Kolodziejczyk C, Klausen Fredslund E, Poulsen PB, Dybro L, Paaske Johnsen S. Costs of major intracranial, gastrointestinal and other bleeding events in patients with atrial fibrillation-a nationwide cohort study. BMC Health Serv Res 2017;17(01):398

3 Inohara T, Xian Y, Liang L, et al. Association of intracerebral hemorrhage among patients taking non-vitamin $\mathrm{K}$ antagonist vs vitamin $\mathrm{K}$ antagonist oral anticoagulants with in-hospital mortality. JAMA 2018;319(05):463-473

4 Deitelzweig S, Neuman WR, Lingohr-Smith M, Menges B, Lin J. Incremental economic burden associated with major bleeding among atrial fibrillation patients treated with factor Xa inhibitors. J Med Econ 2017;20(12):1217-1223

5 Angamo MT, Chalmers L, Curtain CM, Bereznicki LR. Adversedrug-reaction-related hospitalisations in developed and developing countries: a review of prevalence and contributing factors. Drug Saf 2016;39(09):847-857

6 H CUP. Introduction to the HCUP Nationwide Readmissions Database (NRD). 2010-2016. Available at: https://www.hcupus.ahrq.gov/db/nation/nrd/Introduction_NRD_2010-2016.jsp. Accessed November 15, 2019

7 Cunningham A, Stein CM, Chung CP, Daugherty JR, Smalley WE, Ray WA. An automated database case definition for serious bleeding related to oral anticoagulant use. Pharmacoepidemiol Drug Saf 2011;20(06):560-566

8 Joos C, Lawrence K, Jones AE, Johnson SA, Witt DM. Accuracy of ICD-10 codes for identifying hospitalizations for acute anticoagulation therapy-related bleeding events. Thromb Res 2019; 181:71-76

9 United States Census Bureau American Fact Finder. Annual estimates of the resident population by sex, race, and Hispanic origin for the United States, States, and Counties: April 1, 2010 to July 1, 2016. 2017. Available at: https://factfinder.census.gov/faces/ tableservices/jsf/pages/productview.xhtml?src=bkmk. Accessed October 21, 2019

10 Benchimol EI, Smeeth L, Guttmann ARECORD Working Committee. , et al; The REporting of studies Conducted using Observational Routinely-collected health Data (RECORD) statement. PLoS Med 2015;12(10):e1001885

11 Siddique MS, Gregson BA, Fernandes HM, et al. Comparative study of traumatic and spontaneous intracerebral hemorrhage. J Neurosurg 2002;96(01):86-89

12 Shehab N, Ziemba R, Campbell KN, et al. Assessment of ICD-10-CM code assignment validity for case finding of outpatient anticoagulant-related bleeding among Medicare beneficiaries. Pharmacoepidemiol Drug Saf 2019;28(07):951-964

13 Steinberg BA, Gao H, Shrader PGARFIELD-AF ORBIT-AF Investigators. , et al; International trends in clinical characteristics and oral anticoagulation treatment for patients with atrial fibrillation: results from the GARFIELD-AF, ORBIT-AF I, and ORBIT-AF II registries. Am Heart J 2017;194:132-140

14 Hsu JC, Maddox TM, Kennedy KF, et al. Oral anticoagulant therapy prescriptions in patients with atrial fibrillation across the spectrum of stroke risk: insights from the NCDR PINNACLE Registry. JAMA Cardiol 2016;1(01):55-62

15 Gandhi SK, Salmon W, Kong SX, Zhao SZ. Administrative databases and outcomes assessment: an overview of issues and potential utility. J Manag Care Spec Pharm 1999;5:215-222 